\title{
DESIGN OF SQUARE MICROSTRIP PATCH MULTI BAND ANTENNA FOR WIRELESS COMMUNICATION USING EBG STRUCTURE
}

\author{
Suresh Akkole ${ }^{1}$, Dr. N Vasudevan ${ }^{2}$ \\ ${ }^{I}$ Research Scholor, Hindustan Institute of Technology and Science, Padur, Chennai. ${ }^{2}$ Research Scholor, Hindustan Institute of \\ Technology and Science, Padur, Chennai. \\ ${ }^{1}$ sureshakkole@yahoo.co.in, ${ }^{2}$ deanacademics@hindustanuniv.ac.in
}

\begin{abstract}
Application of electromagnetic band-gap (EBG) structure and its use in the design of antenna and microwave integrated circuits is becoming more attractive. The recent electromagnetic band-gap structure method is capturing more importance in antenna design due to its uniqueness properties to suppress the propagation of surface waves in microstrip patch antenna. In this paper a square microstrip antenna is designed and its performance parameters are compared with geometry designed on EBG structure. The square antenna of $29 \mathrm{~mm} \times 29 \mathrm{~mm}$ size is designed at $2.455 \mathrm{GHz}$ and analysis is done using IE3D simulation software. The proposed work mainly focuses on modification of antenna using electronic band gap structure (EBG). The antenna parameters such as Return loss, VSWR, Gain and Bandwidth, with and without EBG are obtained using IE3D simulation tool. The Electromagnetic band-gap structures have been used to improve the performance of the gain of the antennas and radiation patterns. One of the main advantages of electromagnetic band-gap structure is its ability to suppress the surface wave current present on the microstrip antenna. Combining the square patch with EBG structure, the bandwidth of the antenna has been increased by $34.66 \%$, and attained gain of $44.44 \%$ at resonant frequency around $2.4 \mathrm{GHz}$ as compared to the antenna without EBG..
\end{abstract}

Keywords: Eectronic band gap structure (EBG), Return Loss, Microstrip Patch Antenna , VSWR, Multiband antennas

\section{Introduction}

In the present scenario there has been a tremendous evergrowing demand, for planar antennas especially microstrip antenna designs and fabrications for consumer and defense applications because of their attractive features (thin, having small size, conformal and operating in multi-band). Conventional antennas generally operate at a single frequency band, where a different antennas are needed for separate communication applications. Hence there exists the need of requirement of large space for different antennas. In order to overcome this problem, multi frequency microstrip antenna can be used where a single antenna can operate at many different frequency bands. As stated earlier, microstrip patch antennas are suitable for dual-band and/or multi-band wireless applications.

There are a number of approaches and methods that have been suggested over the past years by several researchers which can be used to achieve one or more of these design objectives [1, 2]. Since conventional micro strip antennas have a conducting patch generally fabricated on a grounded dielectric material and operates as resonant cavity elements therefore its operation leads naturally to a narrow impedance bandwidth which is a drawback for micro strip antenna applications in wireless telecommunications system also the radiation of electromagnetic energy in different directions from the radiating element and excitation of surface waves that are formed in the dielectric substrate layer. Because of this when a patch antenna radiates the undesired surface waves trap a portion of total available radiated power along the surface of the substrate, due to this reason i.e. generation of surface waves decreases the antenna efficiency and degrades the antenna patterns [3-4].

In order to improve the antenna performance the electromagnetic band gap (EBG) structure method is employed on microstrip antenna. Due to possession of its periodic lattices, the electromagnetic band gap structure can provide effective and flexible control over the propagation of the electromagnetic waves within a particular frequency band. The electromagnetic band gap structures exhibit multiband, increase impedance bandwidth and improve the input return loss $S_{11}$ of microstrip patch antenna by suppressing the unwanted surface waves as shown in Figure 1[5]. The application of electromagnetic band gap structures in microstrip patch antenna design allows enhancement of gain, 
increased directivity, widening of impedance bandwidth occurs [6].

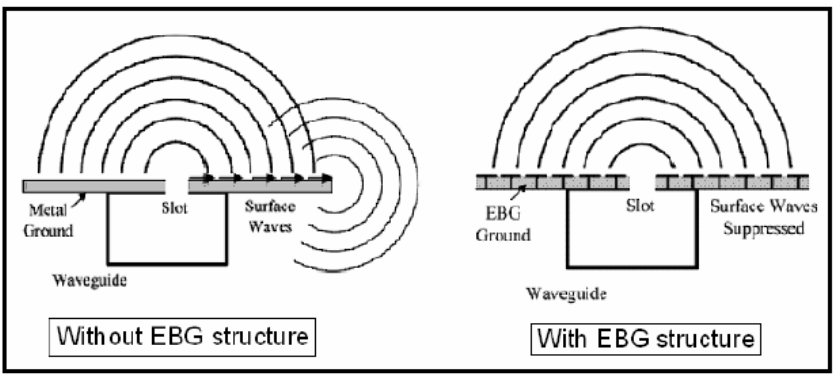

Figure 1: The suppression of surface waves by EBG structure [5].

In this work, the proposed design offers multi frequency operation with wide bandwidth and good gain. These results are obtained by making use of EBG structure. The simulation results show that the designed square microstrip antenna with EBG resonates at multiband frequencies with improved impedance bandwidth, increased return loss, and improved antenna gain. Therefore, the enhancement of the bandwidth, the achievement of multi frequency and enhancement of gain of square patch antenna is proposed by EBG. Section 2 covers Antenna design. Results and discussions are presented in Section 3 followed by its conclusions in Section 4.

\section{Antenna Design}

\section{A. Antenna 1, Square Microstrip Without Ebg Structure}

The microstrip antenna is fed with coaxial probe and a square microstrip antenna size is related to the center frequency $f_{\mathrm{r}}$. In the proposed design of square microstrip antenna without EBG, the Length "L" and width "W" of the patch antenna performs an important role in determining the resonant frequency of operation patch antenna. For square Microstrip antennas, the length (L) and width (W) of the radiating patch antenna maintained at $29 \mathrm{~mm}$ and the effective dielectric permittivity of the microstrip patch antenna $\left(\varepsilon_{\mathrm{r}}\right)$ at the required resonant frequency as it supports the operation of patch or $\lambda_{0}$ which is wavelength of free-space and can be designed using the antenna design equations 1 to 5 as given in [7-8]

$$
\begin{aligned}
& W=\left(\frac{c}{2 f r}\right)\left(\frac{\sqrt{2}}{\sqrt{\varepsilon r+1)}}-----------1\right. \\
& \varepsilon r_{\text {eff }}=\frac{\varepsilon \mathrm{r}+1}{2}+\frac{\varepsilon \mathrm{r}-1}{2} \sqrt{1+12 \mathrm{~h} / \mathrm{w}}-----2 \\
& L=\frac{c}{2 f r \sqrt{\varepsilon r_{\text {eff }} f}}-\cdots-\cdots \\
& \Delta L=L+2 \Delta L-----4
\end{aligned}
$$

$$
\Delta L=0.412 h \frac{\left(\varepsilon r_{\text {eff }}+0.3\right)\left(\frac{w}{h}+0.264\right)}{\left(\varepsilon r_{\text {eff }}-0.258\right)\left(\frac{w}{h}+0.8\right)}--5
$$

where

$\varepsilon_{\text {reff }}=$ Effective dielectric constant

$\varepsilon_{\mathrm{r}}=$ Dielectric constant of substrate

$h=$ Height of dielectric substrate

$\mathrm{W}=$ Width of the patch

$\Delta \mathrm{L}=$ Extension of patch Length

The antenna is optimized using IE3D simulation software ver. 15 . The antenna 1 is designed on dielectric substrate FR-4 with $\mathrm{\varepsilon r}=4.4$ as the dielectric constant, substrate thickness 1.6 $\mathrm{mm}$, and the loss tangent $=0.02$. The antenna designed values are optimized with IE3D antenna simulation software tool. The optimization was performed with number of iterations for the best impedance bandwidth, gain and for multiband operation. Figure 1 shows the geometry of the proposed antenna. The overall dimension of the antenna is $29 \mathrm{~mm} \times 29$ $\mathrm{mm}$.

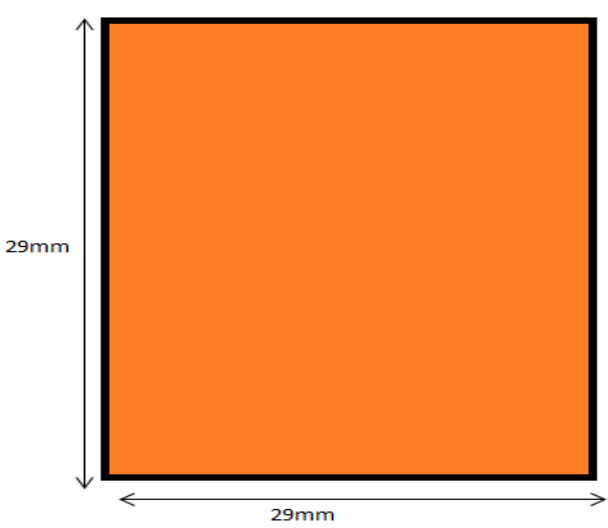

Figure 2. Basic square microstrip antenna.

\section{B. Antenna 2, Square Microstrip With Ebg Structure}

Figure 3 shows the configuration of the proposed square antenna with electronic band gap structure of square of $6.5 \mathrm{~mm}$ size with $1 \mathrm{~mm}$ gap between them. This structure is compact which has good potential to give high efficiency antenna surface and to build low profile. The antenna is simulated using IE3D simulation software Ver 15. The antenna 2 is designed using substrate FR-4 with $\mathrm{er}=4.4$ as the dielectric constant, substrate thickness $1.6 \mathrm{~mm}$, and the loss tangent = 0.02. The antenna designed values are optimized with IE3D antenna simulation software tool. The optimization was performed with number of iterations for the best impedance bandwidth, gain and for multiband operation. Figure 2 shows the geometry of the proposed antenna. The probe feeding technique is being used. The overall dimension of the antenna with EBG structures is $44 \mathrm{~mm} \times 44 \mathrm{~mm}$. 


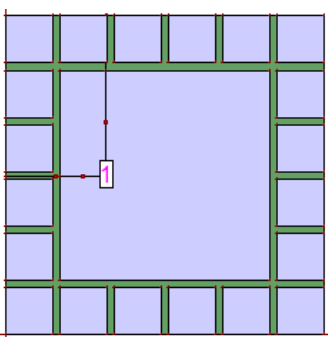

Figure 3.Square Microstrip Antenna with EBG structure

\section{Results And Discussion}

Methods to increase gain can be acquired by changing the material or by use of substrate, but by using simple design and applying EBG structure on patch a well desired gain as well bandwidth can be obtained. Many optimizations are performed by changing the EBG size to obtain optimum values of radiating parameters as listed in Table 1 . Figure 4 shows the comparative analysis of return loss $\left(\mathrm{S}_{11}\right)$ for the proposed antennas 1 and 2. The Figures 5 and 6 show the 2D radiation patterns of the proposed antennas 1 and 2 .

Table 1. Design parameters with optimized values.

\begin{tabular}{|l|l|l|l|l|}
\hline $\begin{array}{l}\text { Type of } \\
\text { Antenna }\end{array}$ & $\begin{array}{l}\text { Resonant } \\
\text { Frequency }\end{array}$ & $\begin{array}{l}\text { VSWR } \\
\text { In dB }\end{array}$ & $\begin{array}{l}\text { BW } \\
\text { In MHz }\end{array}$ & $\begin{array}{l}\text { Gain } \\
\mathrm{db}\end{array}$ \\
\hline \multirow{4}{*}{$\begin{array}{l}\text { Without } \\
\text { EBG }\end{array}$} & 2.44914 & -23.4234 & 49.0927 & -3.239 \\
\cline { 2 - 5 } & 4.49829 & -14.0018 & 111.0170 & -2.807 \\
\cline { 2 - 5 } & 5.51057 & -11.4546 & 60.4930 & -8.310 \\
\cline { 2 - 5 } & 7.28298 & -25.1392 & 172.1380 & 0.287 \\
\cline { 2 - 5 } & 8.97482 & -27.6555 & 176.1940 & -7.782 \\
\cline { 2 - 5 } & 12.3907 & -13.057 & 165.112 & 7.618 \\
\hline \multirow{3}{*}{ With } & 2.3957 & 16.9489 & 75.511 & 2.590 \\
\cline { 2 - 5 } EBG & 4.7432 & 17.4004 & 131.794 & 2.540 \\
\cline { 2 - 5 } & 5.46828 & 24.2630 & 178.797 & 0.581 \\
\hline
\end{tabular}

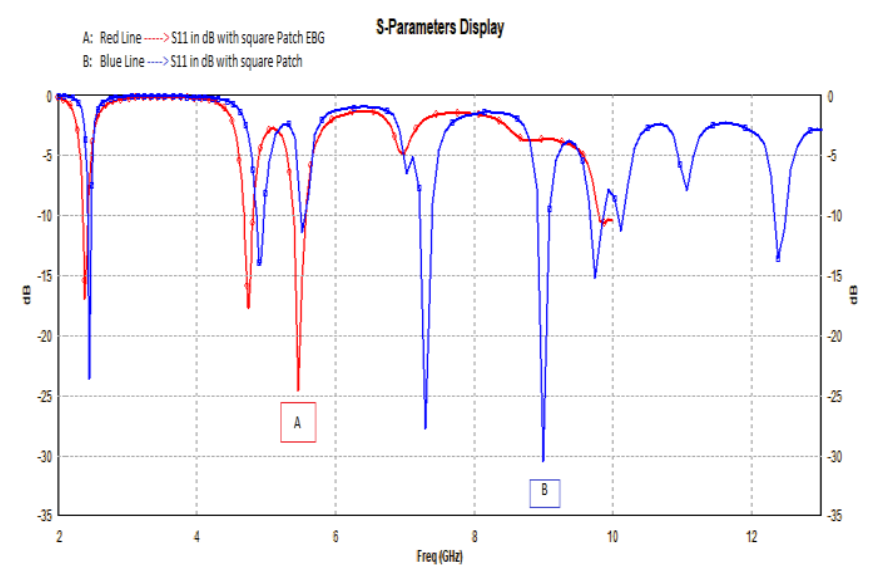

Figure 4. Comparison of S11 characteristics of square microstrip antenna with and without EBG.

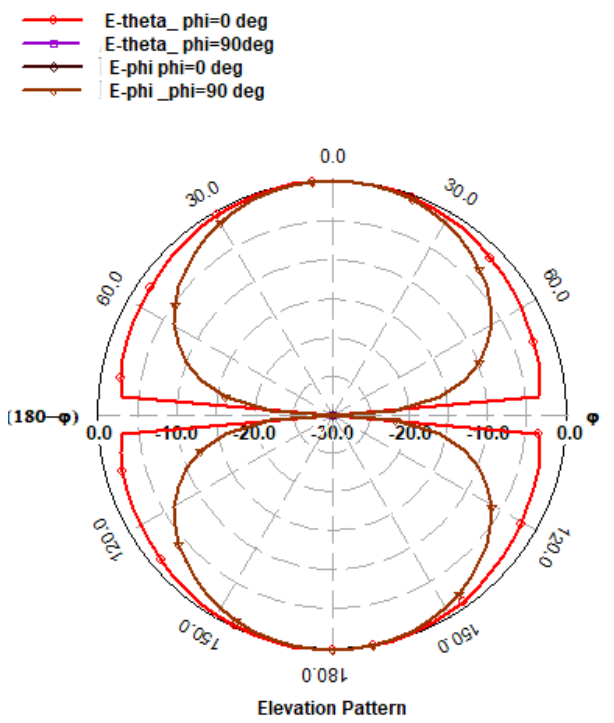

Figure 5. Simulated 2D radiation pattern $(\mathrm{phi}=90)$

The result shows that the antenna 1 (square patch without EBG) has omni-directional radiation pattern at $2.44 \mathrm{GHz}$ as shown in Figure 5. The simulated antenna gain is $-3.2 \mathrm{dbi}$ at $2.44 \mathrm{GHz}$. The antenna 1 operates at multiband having good return loss at frequencies of $2.44914 \mathrm{GHz}, 4.49829 \mathrm{GHz}$ \& $5.51057 \mathrm{GHz}, 7.28298$ 8.9748212.3907 with BW of 49.0927 $\mathrm{MHz}, 111.0170 \mathrm{MHz}, 60.4930 \mathrm{MHz}, 172.1380 \mathrm{MHz}$, 176.1940 $\mathrm{MHz} \& 165.112 \mathrm{MHz}$ with gain of $-3.239 \mathrm{~dB}$, $2.807 \mathrm{~dB},-8.310 \mathrm{~dB}, 0.287 \mathrm{~dB}$, and $-7.782 \mathrm{~dB}$ respectively which are well suited for ISM and Bluetooth.The antenna radiation pattern shows omni-directional characteristics.
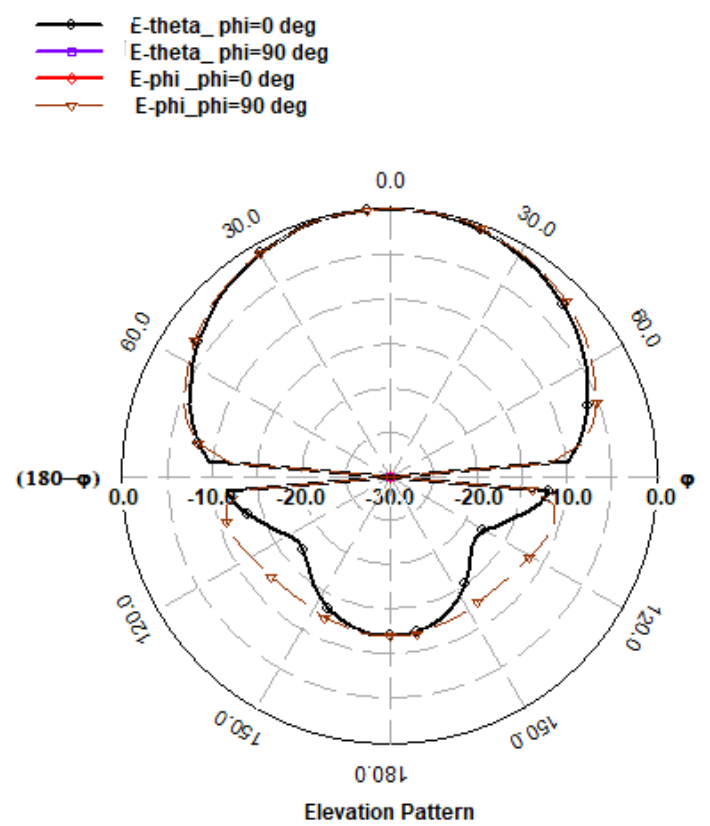

Figure 6 . Simulated $2 \mathrm{D}$ radiation pattern $(\mathrm{phi}=90)$

The antenna 2 (square microstrip antenna with EBG) operates with multiband characteristics having good return loss of $16.9489 \mathrm{~dB}, \quad 17.4004 \mathrm{~dB} \& 24.2630 \mathrm{~dB}$ at resonant frequencies $2.3957 \mathrm{GHz}, 4.7432 \mathrm{GHz} \& 5.46828 \mathrm{GHz}$ with 
BW of $75.511 \mathrm{MHz}, 131.794 \mathrm{MHz} \& 178.797 \mathrm{MHz}$ and gain of $2.590 \mathrm{~dB}, 2.540 \mathrm{~dB} \& 0.581 \mathrm{~dB}$ respectively which are well suited for ISM, Bluetooth, Wi-Fi and Wi-Max applications. The antenna radiation pattern shows omnidirectional characteristic at $2.3957 \mathrm{GHz}$. The diagram depicts that antenna 2 (square microstrip antenna with EBG) is more directive and has higher gain and BW with respect to antenna 1 .

\section{Conclusion}

Square shaped patch antenna with EBG structures has been presented. The presented geometry shows overall optimum results compared to the conventional squarer microstrip antenna. From the proposed antenna design and analysis done here, it is clear that the square patch with EBG structure offers better results over conventional square patch. The operating frequencies obtained with optimum results are $2.3957 \mathrm{GHz}$ with the $\mathrm{BW}$ of $75.511 \mathrm{MHz}$ and $5.46828 \mathrm{GHz}$ with $\mathrm{BW}$ of 178.797MHz. These frequencies are useful for applications in $\mathrm{S}$ band (unlicensed applications) like Wi-Fi, ISM, LTE, and Blue tooth modules. The third frequency is obtained at 4.7432 $\mathrm{GHz}$ frequency with a bandwidth of $131.794 \mathrm{MHz}$ and Gain of $2.540 \mathrm{~dB}$. With these results the proposed geometry is suitable for WIMAX applications.

\section{References}

[1] B. Zoubiri, A. Mayouf, F. Mayouf, S. Abdelkebir, and T. Devers "Rectangular Microstrip Antenna Gain Enhancement Using Elliptical EBG Structure" IEEE Conference Publications pp. 386 - 388, 2016

[2] Sangeetha Velan, Esther Florence Sundarsingh, Malathi Kanagasabai, AswathyK. Sarma, Chinnambeti Raviteja, Ramprabhu Sivasamy,and JayaramKizhekke Pakkathillam "Dual-Band EBG Integrated Monopole Antenna Deploying Fractal Geometry for Wearable Applications" IEEE Antennas and Wireless Propagation Letters, vol.14, 2015

[3] B. Sakthi Abirami and Esther Florence Sundarsingh "EBG-Backed Flexible Printed Yagi-Uda Antenna for On-Body Communication" IEEE Transactions on Antennas and Propagation, vol. 65, no. 7, July, 2017

[4] M. Saberi dalenjan. P. Rezaei, M. Akbari, Sh. Gupta , and A.R Sebak " Radiation Ptoperties Enhancement od A Microstrip Antenna Using A New UC- EBG Structure" IEEE Conference Publications , pp 386 - 388, 2016
[5] S. Jagadeesha,, R. M. Vani and P. V. Hunagund "A Self-Similar Fractal Antenna with Square EBG Structure" International Journal of Engineering Research \& Technology (IJERT) Vol. 2 Issue 2, February- 2013 ISSN: 2278-0181

[6] Payandehoo, K.; Abhari, R, "Employing EBG structure in multi antenna systems for improving isolation and diversity gain, "Antenna and wireless propagation Letters, IEEE, vol.8, pp.1162-1165, 2009.

[7] Ramesh Garg, Prakash Bartia, Inder Bhal andApsiak Ittipiboon, Microstrip Antenna Design Hand Book, Artech House, Norwood, MA, 2001

[8] Balanis, Constantine, Antenna Theory Analysis and Design, John Wiley \& Sons Ltd.,2005

[9] O, Y, Esselle, K.P. Small EBG resonator High-gain antenna using inphase highly-reflecting surface," Electronics Letters, vol.45, No21 pp.1058-1060, October 82009.

[10] Y.Qian,R. Coccioli, D.Sievenpiper, V. Radisic,E.Yablonovitch, and T.Itoh, "A microstrip patch antenna using novel photonic band gap structures," Microwave Journal., pp.66-76, Jan. 1999.

[11] Ban-Leong Ooi, Senior Member, IEEE "A Modified Contour Integral Analysis for Sierpinski Fractal Carpet Antenna With and Without Electromagnetic Band Gap Ground Plane" IEEE Transactions on Antennas and Propagation, vol.52, no.5, May 2004.

[12] Y. Qian R. Coccioli, d. Sievenpiper, V. Radisic, E. Yablobnovitch and T.Itoh, "A Microstrip patch antenna using novel photonic band gap structures" Micowave Journal, pp.66-76, Jan. 1991.

[13] John D Krauss, Ronald J Marhefka and Ahmad S. Khan, Antennas and Wave Propagation, Fourth Edition, Tata McGraw Hill, 2010 Special Indian Edition.

[14] S. Jagadeesha,, R. M. Vani, P. V. Hunagund "Plus Shape Slotted Fractal Antenna for Wireless Applications "Wireless Engineering and Technology, Scientific Research Journal, 2012, 3, 175-180.

[15] Girish Kumar \& K.P. Ray, Broadband Microstrip Antennas, Artech House, Boston 